\title{
A taxonomia deleuziana e as relações de gênero no filme "A Garota Dinamarquesa"
}

\author{
The Deleuzian taxonomy and the gender relations in the film "The Danish \\ Girl"
}

Georgia Mattos - Universidade de Sorocaba | Sorocaba | São Paulo | Brasil | E-mail: georgia.jor@gmail.com

Luís Roberto Albano Bueno da Silva - Universidade de Sorocaba | Sorocaba | São Paulo |Brasil | e-mail: luis.silva@prof.uniso.br

Resumo: O artigo tem como propósito realizar uma análise fílmica a partir da taxonomia de Deleuze, precisamente em seu estudo sobre imagem-movimento, que consiste em verificar na montagem de um determinado filme, os enquadramentos utilizados e analisar através de sua taxonomia (afecção, ação e percepção) os efeitos que esta causa num/a determinado/a espectador/a. O filme A Garota Dinamarquesa, por sua vez, retrata a história de Lili Elbe, uma das primeiras transexuais a se submeter à cirurgia de redesignação sexual, a partir disso, interessa-nos, além da análise fílmica, compreender as relações de gênero construídas no filme. Para isso, debruçamo-nos sobre os estudos queer, precisamente, em alguns conceitos de Judith Butler. Percebemos que as teorias apresentadas se fazem valer mais fortemente na passagem imagética da montagem do filme e enquadramento, ao mesmo tempo em que roteiro e fala são menos explícitos nesse aspecto.

Palavras-chave: Imagem-movimento. Estudos Queer. Análise fílmica.

Abstract: The paper has as its purpose accomplish a film analysis by the Deleuze taxonomy, precisely in his studies of image-movement, that consists in to verify the cut of any movie, its framework and analyze through a taxonomy (affection, action, and perception) the effects that a movie can cause in any viewer. The movie chosen for the analysis is The Danish Girl, that shows the story of Lili Elbe, one of the first transexuals that are submitted to a sexual reassignment surgery; from that, interest us, beyond the film analysis, understand the gender relations built in the movie. For that, we lay down over queer studies, precisely over Judith Butler concepts. We perceive that the presented theories are more visible in the imagetic movement of the movie cut and its framework, at the same time that the script and speech are less explicit in this aspect.

Keywords: Image-movement. Queer studies. Film analysis.

https://doi.org/10.22484/2177-5788.2018v44n2p241-266

Recebido em setembro de 2018. $\quad$ Aprovado em outubro de 2018. 


\section{Introdução}

Neste trabalho, buscamos entender as relações de gênero que estão imbricadas no filme A Garota Dinamarquesa, que retrata a história de Lili Elbe, uma das primeiras transexuais a se submeter à cirurgia de redesignação sexual no início do século passado. Dada a importância de questões como estas em nossa sociedade atualmente, acreditamos ser pertinente refletir sobre as mesmas a partir do viés teórico desenvolvido por Judith Butler, autora de estudos queer que compreende as identidades generificadas e sexuadas como formações subjetivas, construídas no interior das estruturas de poder.

Além da reflexão butleriana sobre o conteúdo construído no filme, pretendemos ainda trabalhar a forma como o filme abordou a questão da transexualidade através da teoria taxonômica deleuziana. Para esta análise, utilizamos a teoria de imagem-movimento, que visa entender por meio das leituras bergsonianas e peirceanas o modo como a montagem e os cortes de um filme impacta a experiência do/a espectador/a.

\section{A imagem-movimento de Deleuze e sua taxonomia de análise fílmica}

Em seu livro Cinema 1 - A imagem-movimento, Gilles Deleuze (1983) buscou desenvolver uma taxonomia do cinema clássico, onde se aprofundou especificamente nas teorias do movimento, pensadas e discutidas inicialmente por Henri Bergson, em sua obra Matéria e Memória, como também nas teorias fenomenológicas elaboradas por Charles Sanders Peirce. Importante dizer que sua obra não se resume apenas na relação e crítica das teorias destes dois autores, bem como em apenas buscar uma taxonomia final dentro da análise fílmica. Tanto A imagem-movimento quanto A imagem-tempo são obras bastante profundas quando da compreensão de nuances do cinema, além de tratar das relações do cinema com a história humana, e o modo como o cinema impacta no desenvolvimento humano. Especificamente para este artigo, serão 
trabalhadas apenas as questões relativas à classificação. Esta ressalva se faz importante para que não se tenha uma visão exclusivamente técnica da obra deleuziana: em princípio, sua obra é filosófica. Feito este aviso, para compreender os fundamentos de sua teoria como base para análise fílmica, é necessário o entendimento anterior de alguns conceitos relativos ao movimento e à fenomenologia.

O pensamento tradicional de movimento no cinema é guiado pelo senso comum da movimentação e troca de quadros ou frames - imagens estáticas enfileiradas que dão lugar umas às outras na ordem da fila, em uma determinada frequência de troca -, normalmente, numa frequência de 24 quadros por segundo. Esse é um tecnicismo, que apesar de correto, não responde totalmente para a compreensão do que Deleuze chamou de imagem-movimento. A imagem-movimento é fruto do estudo e da crítica de três teses sobre movimento vindas de Henri Bergson. De fato, a leitura de Deleuze diz que a primeira tese apenas introduz as outras duas, porém todas relacionadas a questões relativas ao movimento. Em sua primeira tese, Bergson atenta para que não se confunda espaço percorrido com movimento. O espaço percorrido pode ser dividido em pontos infinitamente pequenos e distintos, enquanto o movimento não. Esse conceito é importante, pois o movimento dita o que Deleuze posteriormente chama de Todo, ou seja, a completude de uma duração. A divisão de um espaço percorrido não muda a natureza do espaço, porém a divisão de um movimento muda. O movimento seria, nesse sentido, a translação de pontos específicos num determinado período de tempo, que satisfaz uma alteração do Todo num período de duração. Esse seria a segunda tese de Bergson, que analisa a diferença entre o pensamento clássico e o pensamento moderno sobre movimento.

0 pensamento clássico privilegiaria 0 instante enquanto 0 pensamento moderno o tempo: no pensamento da filosofia antiga, o movimento era pensado como o conjunto de instantes privilegiados que 
sucedidos, dariam o movimento. 0 pensamento moderno pensa 0 movimento como ordem do posicionamento de pontos dos objetos em função do espaço e do tempo. Deleuze, nesse sentido, valoriza a segunda concepção de movimento, levando ao entendimento da terceira tese bergsoniana da mudança do Todo. Como o movimento é irredutível, composto da variação dos objetos em função do espaço e do tempo, quando há esta movimentação, há impacto no Todo da duração. A modificação que o movimento implica impacta no Todo. Um filme, desse modo, é um todo dependente do movimento de seus objetos em função do tempo. Essas modificações privilegiam a montagem dentro de um filme, onde planos definidos por técnicas cinematográficas fomentam uma imagem indireta do tempo, levado a percepções e reações durante a passagem de tempo e movimento em um filme. Assim, a imagem-movimento nada mais é do que um recorte de um plano de uma determinada duração, que expressa sua essência, pois este representa o movimento e a mudança de um todo. "Em outras palavras, o próprio da imagem-movimento cinematográfica é extrair dos veículos ou dos móveis o movimento que é sua substância comum, ou extrair dos movimentos a mobilidade que é a sua essência". (DELEUZE, 1983, p. 30).

Como a expressão do todo, a imagem-movimento desencadeia naquele que a aprecia percepções e reações, gerando estímulos de açãoreação, trabalhando a expectativa dos sentidos somatossensoriais do apreciador, causando mudança mental. Com isso, Deleuze nos apresenta os tipos de imagem-movimento relacionados às reações possíveis neste jogo de movimento da montagem fílmica; são eles: a imagem-afecção, a imagem-ação e a imagem-percepção. Estas imagens-movimentos estariam ligadas ao predomínio de determinados tipos de planos cinematográficos, sendo eles o primeiro plano, o plano médio e o plano geral, respectivamente. No entanto, para melhor compreender os conceitos envolvidos nestes tipos de imagem-movimento, faz-se necessário o 
conhecimento das bases fenomenológicas peircianas, que é a base para o aprofundamento dado por Deleuze para estas taxonomias. São as categorias fenomenológicas peirciana: a primeiridade, a secundidade e a terceiridade. Estas categorias indicam o modo como os fenômenos do mundo se apresentam a um intérprete, e como este reage. Deleuze utilizou a teoria peirciana em sua obra e, neste sentido, a imagem-movimento faz uso desta base de pensamento, tanto fenomenológica como sígnica.

O primeiro dos níveis apresentados quando da observação de um fenômeno é a primeiridade. A primeiridade é um primeiro momento na percepção do universo, em que este se apresenta de forma qualitativa e potencial. Nela, percebe-se o universo em suas qualidades materiais mais básicas, em níveis quase sinestésicos. Cores, formas, odores, movimentos se apresentam, sempre em potencial das possibilidades do que possa o levar a ser. É importante considerar que em primeiridade, o abstrato e as qualidades de sentimento prevalecem, as percepções iniciais do universo são atemporais e não indicam o apresentado. Isto significa que, em primeiridade, apenas tem-se o potencial do devir, mas não é possível ainda discriminar exatamente o que está sendo presenciando. A imagem-afecção está fortemente ligada à primeiridade. Desenvolvida em primeiro plano, ou close, esta leva o intérprete ao que Deleuze chamou de "lugar qualquer", pois tira o observado de uma posição espacial determinada, rostificando-a. Essa ideia de rostificação em lugares quaisquer leva o intérprete a uma posição do puro sentir, buscando a identificação com o que é familiar. "Nessas condições, quando nossa face receptiva imobilizada absorve um movimento em vez de refleti-lo, nossa atividade não pode mais responder senão por uma 'tendência', um 'esforço', que substituem a ação, ação que se tornou momentânea ou localmente impossível" (DELEUZE, 1983, p. 79). Nessa busca do familiar, o desconforto pode acontecer, bem como a identificação. O rosto, para Deleuze, não necessariamente está ligado a uma face humana: há uma questão de humanização; de familiarização com 
os potenciais e qualidades mais básicos que nos fazem humanos. Essa rostização em primeiro plano reforça a questão do movimento na base histórica do intérprete, pois busca nele suas bases qualitativas mais profundas. Também cria nele um reforço de sentir, estético, mudando sua percepção emocional no momento do vislumbre ou do acontecimento.

Há, portanto, uma relação da afeç̧ão com o movimento em geral, que se poderia enunciar assim: o movimento de translação, em sua propagação direta, não é apenas interrompido por um intervalo que distribui de um lado o movimento recebido, de outro o movimento executado, e que os tornaria de certo modo incomensuráveis. Entre os dois há a afecção, que restabelece a relação; mas, precisamente, na afecção o movimento deixa de ser de translação para tornar-se movimento de expressão, isto é, qualidade, simples tendência que agita um elemento imóvel. Não é de se espantar que, na imagem que somos, seja o rosto, com sua imobilidade relativa e seus órgãos receptores, que faça aflorar tais movimentos de expressão, enquanto no resto do corpo permanecem quase sempre soterrados. (DELEUZE, 1983, p. 79).

Há um momento de passagem de primeiridade para secundidade, do sentir para o perceber. Quando o close se abre para um plano médio ou aberto, há uma busca pelo real, pelo existente, num momento de difícil perceber. "O que faz com que a imagem-pulsão seja tão difícil de ser atingida e até mesmo de ser definida ou identificada é que ela está, de certo modo, imprensada entre a imagem-afecção e a imagem-ação." (DELEUZE, 1983, p. 155). Há um potencial de ação. Nesse momento, entre primeiridade e secundidade, entre afecção e ação, Deleuze nos dita o que chamou de imagem-pulsão. A imagem pulsão está num mundo originário, onde os espaços são indeterminados, mas há um realismo aí. É um momento intermediário de rostidade reflexiva, quase surrealista. Há um 
super-realismo, um algo que se fixa ao olhar, com força de rostidade, uma identificação real, porém sem lugar.

Em secundidade, tem-se a indicação daquilo que é efetivamente apresentado. Aqui tem a sensação da singularidade e do temporal, em que, de fato, os elementos que antes eram qualidades abstratas se tornam algo concreto e indicativo, algo distinguível. A secundidade procede da primeiridade no nível concreto, quando as qualidades inicialmente apresentadas são comparadas com qualidades já existentes na experiência do intérprete. Essas comparações, aliadas a questões de localização do apresentado, tanto em função espacial quanto temporal, fazem com que seja possível identificar determinado fenômeno, indicando-o. Segundo Drigo e Souza (2013, p. 31):

O segundo fundamento ou passaporte para que qualquer coisa funcione como signo é o fato de algo ser um existente, lembrando que algo existente é também algo que resiste à nossa vontade. Ação, reação, conflito são palavras-chave desse segundo fundamento. Em toda experiência, quer seja de objetos exteriores ou interiores, há sempre um elemento de reação, anterior à medida do pensamento articulado e posterior ao puro sentir.

Além disso, a secundidade é embativa. Nela, como as questões de espaço e tempo estão explicitadas de forma patente, é possível sentir o embate do ambiente e a invasão deste ao intérprete. Não é possível controlar o que é percebido, pois este se força contra aquele que recebe o estímulo. Os estímulos na secundidade também são resistentes, onde há a forçosa relação com o concreto. Quando forçosamente tem-se a percepção do universo, movimentos internos podem levar o intérprete a uma compreensão mais aprofundada do apresentado, além do embate.

"As reações que um sinsigno podem provocar, são [...] uma constatação. Logo, um intérprete diante da obra pode constatar de que se trata de uma pintura; outro, pode reconhecer como sendo de Van Gogh". (DRIGO; SOUZA, 2013, p. 35). 
A imagem-ação encontra-se na seara da secundidade. Aqui, há forçosamente um realismo, em que o meio e o comportamento de um personagem, ou condição, sobressaem a uma questão mais potencial ou sentimental. Deleuze (1983) indica que há uma questão de situação e ação a ser observada, onde algo predomina a pura reação ao meio, e uma tomada de decisão puramente embativa. Não se percebe nada senão o contraponto de uma ação sobre uma situação. Deleuze (1983, p. 143) sintetiza esclarecendo que:

Quando as qualidades e potências são apreendidas enquanto atualizadas em estados de coisas, em meios geográfica e historicamente determináveis, entramos no campo da imagemação. O realismo da imagem-ação se opõe ao idealismo da imagemafecção. $E$, no entanto, entre os dois, entre a primeiridade e a secundidade, há algo que é como o afeto "degenerado", ou a ação "embrionada". Não é mais imagem-afecção, mas não é ainda imagem-ação.

A terceiridade é a entrada final do fenômeno, no qual este é generalizado e se torna signo para Peirce. O signo para Peirce seria, de forma bastante sucinta, um intermediador do universo para um intérprete ou coisa. O signo, como intermediador, só existe quando produz mudança, no sentido de criar algo novo. Esse novo acontece em terceiridade, ou seja, quando há uma movimentação mental de um intérprete para o novo. A generalização ocorre quando se percebe o fenômeno como fenômeno, possuidor de uma regra ou lei de geração. Há então um cognoscível, ou seja, algo passível de reflexão e ampliação. Novamente, Drigo e Souza (2013, p. 34) esclarecem:

O terceiro fundamento que dá a um signo o atributo de ser genuíno é a lei, a generalidade. No processo interpretativo, as inferências se submetem ao governo da camada mediadora da intencionalidade, da razão. Não há como fazer a cadeia sígnica caminhar sem esses componentes. É nessa instância que o signo impulsiona o processo de ação dos signos ou a semiose. Atributos como conhecimento, intelecção, arbitrariedade, regularidade, hábito são inerentes nesse domínio do signo. 
A generalização permite a compreensão do fenômeno como oriundo de uma regra, pertencente a um conjunto ou grupo de leis. Isto, no entanto, só é possível se forem realizadas as devidas comparações internas das qualidades dos existentes, identificando-os para que, de forma geral, seja possível classificá-los e indicá-los como parte de um conjunto passível de gerá-los e geri-los. A imagem-percepção reside em terceiridade. $\mathrm{Na}$ verdade, a imagem-percepção pode ser entendida como contempladora dos outros tipos de imagem. Há primeiridade na secundidade, e ambas na terceiridade. Essa completude, entrega à duração um caráter mental, cognoscível, onde num plano geral, tem-se a interferência da mente no processo de percepção e visão do filme. Há aqui um completar mental do filme, onde há raciocínio envolvido.

A imagem-percepção encontra aqui seu signo de composição particular. Tomando emprestada uma expressão de Peirce, poder-se-ia chamá-la de "dicissigno" (mas para Peirce é a proposição em geral, enquanto para nós trata-se do caso especial da proposição indireta livre, ou melhor, da imagem correspondente). A consciência-câmera adquire, então, uma determinação formal elevadíssima. (DELEUZE, 1983, p. 91).

A velocidade do movimento das imagens-afecção e imagem-ação é diminuída, privilegiando o espaço negativo do pensamento do intérprete. É interessante pensar, nesse sentido, que Deleuze faz uma crítica à imagemação: não há apenas reações sensório-motoras oriundas do sentir e perceber nos filmes; há também um cognoscível.

Como no cinema, as categorias e tipos de imagem se completam e se desenvolvem em diferentes níveis e combinações. Fenômenos podem prevalecer conforme o contexto de sua apresentação, mostrando-se eventualmente como uma das categorias (com as devidas anteriores embutidas a ela) ou todas, possibilitando a geração do signo. De fato, apesar de essa classificação parecer um processo linear lento ou ainda 
excludente, é efetivamente rápido e combinado, alterando-se conforme o tempo - novamente - dependente do contexto e de condições anteriores. Além da análise fílmica a partir da taxonomia deleuziana, propomos realizar também uma reflexão sobre as relações de gênero construídas no filme $A$ Garota Dinamarquesa, assim, dedicamos nosso próximo tópico sobre os estudos queer.

\section{Estudos Queer e as relações de gênero na concepção butleriana}

Para discorrermos sobre as relações de gênero, apoiamo-nos no estudo desenvolvido por Judith Butler, que aborda as questões sobre as identidades generificada e sexuada, e por isso mesmo, é considerada uma teórica queer por excelência. Em sua obra Problemas de Gênero, a autora compreende a identidade de gênero - a relação entre sexo, gênero, prática sexual e desejo - enquanto formação subjetiva, construída no interior das estruturas de poder. Para Butler (2003), as estruturas de poder/saber produzem as identidades dentro de uma matriz heterossexual, que permitem que o sujeito só alcance estabilidade e coerência dentro desse modelo.

O sujeito, nesta perspectiva, é sustentado por meio de uma matriz de normas de gênero fortemente estabelecida para manter e estipular uma única forma legítima de ser, na qual, o sexo determina o gênero - masculino ou feminino, e este determina o desejo, direcionado sempre para o sexo oposto. Esta relação forjada é o que a autora chama de "ordem compulsória da heterossexualidade". Desse modo, o sujeito é constituído por práticas reguladoras, quais estabelecem gêneros inteligíveis (aqueles que mantêm a coerência entre sexo, gênero, prática sexual e desejo), sempre mantidos por uma ordem heterossexista. Consequentemente, essa coerência se trata de um ideal normativo e não uma característica descritiva da experiência do sujeito. Assim, "a coerência e a continuidade da pessoa não são características lógicas ou analíticas da condição da pessoa, mas, ao 
contrário, normas de inteligibilidade socialmente instituídas e mantidas" (BUTLER, 2003, p. 38).

A construção desse sujeito, segundo a autora, não passa de uma formação discursiva, que o define e o forma de acordo com os sistemas de poder/saber. Formação discursiva, na vertente foucaultiana, significa um conjunto de enunciados e discursos capaz de produzir "verdades", verdades estas, construídas historicamente e, sendo assim, mudam de acordo com os contextos históricos e estão fortemente situadas nos interesses das relações de poder. Esta ordem compulsória da heterossexualidade, responsável por ditar a inteligibilidade do sujeito, denota ainda a exclusão de qualquer outra possibilidade de identidade, cujo gênero não decorre do sexo, ou aquelas identidades em que as práticas de desejo não decorrem nem do sexo e nem do gênero, são identidades de gênero que não se adequam às normas da inteligibilidade cultural.

Mas o que parece ser uma "incoerência", ou como Butler (2003, p. 39) afirma, "meras falhas do desenvolvimento ou impossibilidades lógicas", na verdade, são possibilidades de problematizar esse padrão, que denuncia que o gênero é culturalmente construído e, além disso, que o sexo não pode mais ser considerado como biologicamente imutável, pois essa formação discursiva, segundo Butler (2003, p. 19),

é dada como natural, a "construção política do sujeito procede vinculada a certos objetivos de legitimação e de exclusão, e essas operações políticas são efetivamente ocultas e naturalizadas por uma análise política que toma as estruturas jurídicas como seu fundamento".

Nesse processo, o sistema jurídico e político de poder legitima certos sujeitos, ao passo que exclui outros - os que não podem ser reconhecidos, ou seja, trata-se de uma posição política que favorece às necessidades estruturais e econômicas de uma sociedade heterossexista. 
Isso permite desestabilizar as normas de gênero, pois o sexo, de acordo com Butler (2003), é tão culturalmente construído quanto o gênero, portanto, o sexo não é tão fixo como se supõe, tampouco o gênero é resultado causal do sexo, mas sim, efeito de uma construção cultural que produz o sexo como pré-discursivo. Na concepção butleriana, o gênero nada mais é do que a inscrição cultural de significado num determinado sexo, mas tanto o gênero quanto o sexo são produzidos discursivamente. Para Butler (2003, p. 25), "o gênero não está para a cultura como o sexo para a natureza", o sexo também é um meio discursivo cultural, em que a natureza é produzida e estabelecida como pré-discursiva ou anterior à cultura. Nesse âmbito, o gênero não pode ser simplesmente entendido como a expressão ou o reflexo do sexo.

Se a sexualidade é construída culturalmente no interior das relações de poder existentes, então a postulação de uma sexualidade normativa que esteja "antes", "fora" ou "além" do poder constitui uma impossibilidade cultural e um sonho politicamente impraticável, que adia a tarefa concreta e contemporânea de repensar as possibilidades nos próprios termos do poder (BUTLER, 2003, p. 55).

Diante disso, Butler (2003) desenvolve a teoria da performatividade de gênero, defendendo que a identidade de gênero é uma prática discursiva contínua, que se constrói a partir da repetição de atos ao longo do tempo, rompendo com a ideia de sexo essencial e de feminilidade ou masculinidade verdadeiras e/ou permanentes. Mas são construídas de tal forma, ao longo do tempo, que ocultam seu caráter performativo, qual incorporamos as marcas de gênero que nos são passadas, ensinadas. Este conceito está relacionado com as teorias linguísticas de J. L. Austin e Derrida, dado que as identidades de gênero são construídas por meio da linguagem, são performativas ao passo que é pela linguagem e pelo discurso que são (re)produzidas, enquanto efeito dos discursos de poder sucedido ao longo 
do tempo. Para Butler, o sujeito é um termo em processo, suas ações não partem propriamente dele, mas das relações culturais.

Com efeito, a fonte da ação pessoal e política não provém do indivíduo, mas se dá nas e pelas trocas culturais complexas entre corpos nos quais a própria identidade é sempre cambiante, em que a própria identidade é construída, desintegrada e recirculada exclusivamente no contexto de um campo dinâmico de relações culturais (BUTLER, 2003, p. 183).

Porém, mesmo que o sujeito seja culturalmente construído, Butler entende que este sujeito também é dotado de ação, que ser constituído pelo discurso não é o mesmo que ser determinado por ele, há sempre a possibilidade de ação. Com isto, surgem as possibilidades de identidades consideradas subversivas, ainda que não seja possível existir toda e qualquer nova possibilidade, como alerta a autora, mas sim, de poder redescrever as possibilidades existentes no domínio da cultura. Essas possibilidades de subversão ocorrem somente dentro dos termos da cultura, visto que não há realidade ou práticas fora dela. Por essa razão, a possibilidade de subversão decorre a partir do repensar criticamente as possibilidades que já existem, assim, segundo Butler (2003), essa conversão não se trata de uma consolidação, mas de um deslocamento.

Como exemplo desse deslocamento, podemos citar as experiências transexuais, que não se limitam ao sistema binário e revelam o quanto as normas reguladoras, que sustentam as identidades generificadas e sexuadas, são fictícias. Essas experiências, e tantas outras possíveis, não subvertem a ponto de romper totalmente com as normas estipuladas, para Butler, isso seria uma impossibilidade cultural; mas sem dúvida, desestruturam essas normas, desmascarando que certas práticas consideradas proibitivas são estabelecidas pelo interesse das estruturas de poder/saber que se justificam em discursos da natureza biológica, quando não passam de discursos políticos. 
Por isso, a importância de identidades de gênero que não se adequam às normas, pois "criam oportunidades críticas de expor os limites e os objetivos reguladores desse campo de inteligibilidade e, consequentemente, de disseminar, nos próprios termos dessa matriz de inteligibilidade, matrizes rivais e subversivas de desordem do gênero" (BUTLER, 2003, p. 39).

São nessas relações arbitrárias que se encontram as possibilidades de transformação de gênero, nos modos de repetição irregulares e desconforme, em que Butler denomina de "repetição parodística". Sua ideia de "paródia de gênero", neste sentido, é o ato de "encenar", ou mesmo, "imitar" as performances de gênero, como por exemplo, as representações feitas por drag queens ou drag kings, que demonstram o quanto as identidades generificadas consideradas coerentemente heterossexuais possuem caráter fictício de essenciais e naturais. "A noção de paródia de gênero aqui defendida não presume a existência de um original que essas identidades parodísticas imitem. Aliás, a paródia que se faz é da própria ideia de um original" (BUTLER, 2003, p. 197).

Ao reconhecermos que não existe uma identidade original, mas atos performativos que incorporamos e repetimos, dos quais funcionam como um conjunto de práticas imitativas que se referem a outras imitações e revelam que o original não passa de uma paródia da ideia de natural e original, fica claro, que a identidade de gênero é um efeito das normas reguladoras que buscam constituir uma identidade original por meios discursivos da heterossexualidade compulsória, que assumem o lugar de uma identidade real e legítima.

Se a verdade interna do gênero é uma fabricação, e se o gênero verdadeiro é uma fantasia instituída e inscrita sobre a superfície dos corpos, então, parece que os gêneros não podem ser nem verdadeiros nem falsos, mas somente produzidos como efeitos da verdade de um discurso sobre a identidade primária e estável. (BUTLER, 2003, p. 195). 
Tomar a verdade da identidade de gênero como efeito dos discursos de poder é perceber que essa verdade foi impelida por uma construção forjada, consequentemente, não existem atos de gênero verdadeiros ou falsos, mas atos que se (re)produzem pelo processo de imitação ao longo do tempo. Por isso, Butler destaca a importância da atuação parodística do gênero para situar as estratégias de repetição com o intuito de averiguar as possibilidades possíveis de intervenção e subversão que facultam a identidade de gênero.

\section{A taxonomia deleuziana e as relações de gênero no filme "A garota dinamarquesa"}

O filme A Garota Dinamarquesa se passa na cidade de Copenhague da década de 1920, dirigido por Tom Hooper, retrata a história de Lili Elbe, umas das primeiras transexuais a se submeter à cirurgia de redesignação sexual. O filme é baseado no livro de ficção de David Ebershoff e não em sua autobiografia Fra mand til kvinde (De homem para mulher) - o que recebeu algumas críticas por omitir detalhes importantes de sua vida ${ }^{1}$, ainda assim, nossa análise se restringe à produção fílmica de sua história.

A seguir, serão analisadas algumas cenas do filme A Garota Dinamarquesa, escolhidas com o intuito de perceber a forma da transição de um estado de imagem-movimento para o outro, buscando compreender como um possível intérprete pode ser impactado dentro da taxonomia proposta do Deleuze.

Na cena escolhida, Einar, interpretado por Eddie Redmayne, está de frente para um espelho, onde passa por um processo de autoanálise e autocrítica com relação à sua identidade de gênero. Esta cena é emblemática dentro da duração total do filme, pois seu recorte em imagem-

\footnotetext{
${ }^{1}$ Como a razão de sua morte, que se deu por complicações pós-operatórias em sua quinta cirurgia de readequação sexual, num processo de transplante de útero; e não em sua segunda cirurgia, para a construção da vagina como o filme apresenta.
} 
movimento atenta não apenas para o enredo do filme, bem como é um ponto catártico na compreensão do personagem principal da trama.

Num primeiro momento, o diretor buscou retratar num plano geral a visão de Einar, em pé, olhando ao espelho (Fig. 1).

Figura 1 - Einar em frente ao espelho

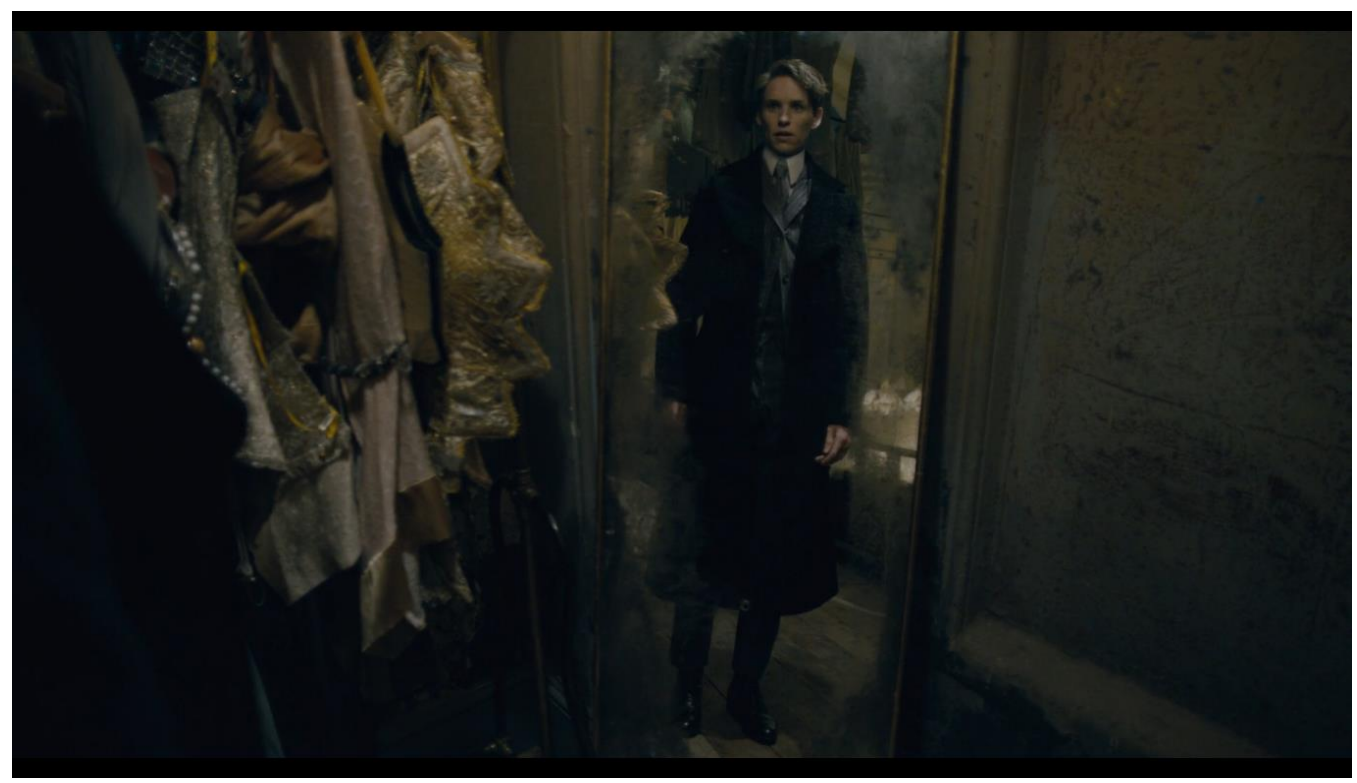

Fonte: A Garota Dinamarquesa (2015).

Isto é bastante claro no corte da cena, em que vemos ao lado esquerdo, roupas femininas; ao centro, um espelho com sua imagem refletida; e ao lado direito, um vazio. Temos uma imagem-percepção nesse instante. A escolha dos elementos dispostos desse modo, num plano geral, não parece ser arbitrária. Além de buscar o posicionamento do intérprete no local de existência do personagem, indica que este é um espaço feminino. As roupas e o espelho denotam isso. Sua imagem masculinizada, dada sua indumentária, causa estranheza e nos faz refletir, em seu olhar perplexo em frente ao espelho, que há um problema com a imagem refletida. Ele não se vê refletido no espelho e aquela imagem não reflete quem ele sente ser. Inicia-se um processo de reflexão. A escolha deste 
plano em imagem-percepção faz com que o/a espectador/a inicie um processo de análise juntamente com Einar.

Ao passar para um primeiro plano, o/a espectador/a está ainda na seara da reflexão, porém temos um processo de passagem da imagempercepção para a imagem-afecção. O cenário desaparece, focando em close apenas no rosto de Einar (Fig. 2). Nesse momento, fica clara a intenção do diretor em mostrar que Einar, agora tentando se reconhecer no espelho, está buscando algo. Há estranheza em seu rosto, algo que nos é comum, há uma rostidade. "Os rostos não são primeiramente individuais, eles definem zonas de frequência ou de probabilidade, delimitam um campo que neutraliza antecipadamente as expressões e conexões rebeldes às significações conformes." (DELEUZE; GUATTARI, 1999, p. 29). O sentir do seu rosto é frustrado, dolorido. Einar não se vê no espelho, não se reconhece. Isso é passado para o/a espectador/a ao focar no sentimento que este denota.

Figura 2 - Rosto de Einar em frente ao espelho

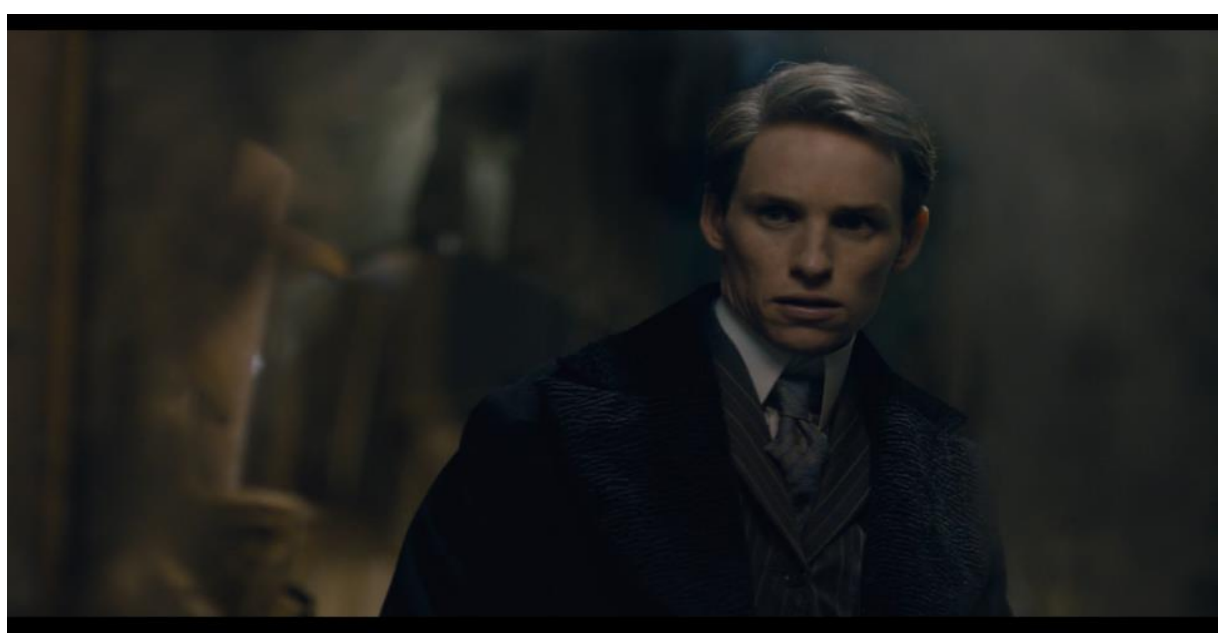

Fonte: A garota dinamarquesa (2015). 
Cria-se uma possibilidade, uma pulsão potencial de ação. A imagempulsão se faz presente, há um impulso, algo a acontecer. Esse algo se faz, ainda em close, focalizando nos detalhes do despir como se indicasse algo que para o/a espectador/a é normal, porém, causando estranheza pela força com que o faz. A rostidade se faz importante, pois esse despir, apesar de ter elementos de imagem-ação, possui um significado estético, canalizado em potencial na imagem-pulsão.

Ao se despir (Fig. 3 e 4), Einar passa por um processo de autoanálise e experimentação, e o espectador é convidado a participar. Einar acaricia seu busto e o força para, esteticamente, parecer aquilo que em seu âmago ele sabe ser (Fig. 5).

Figura 3 - Einar se despindo na frente do espelho

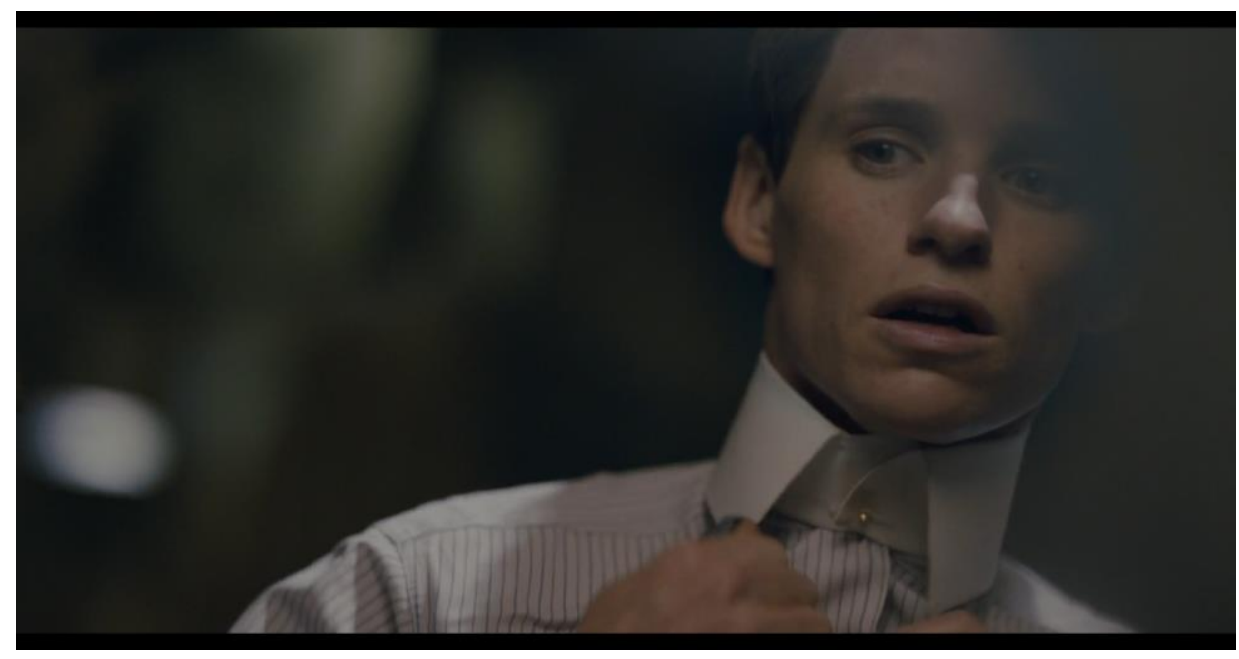

Fonte: A garota dinamarquesa (2015). 
Figura 4 - Ainda se despindo na frente do espelho

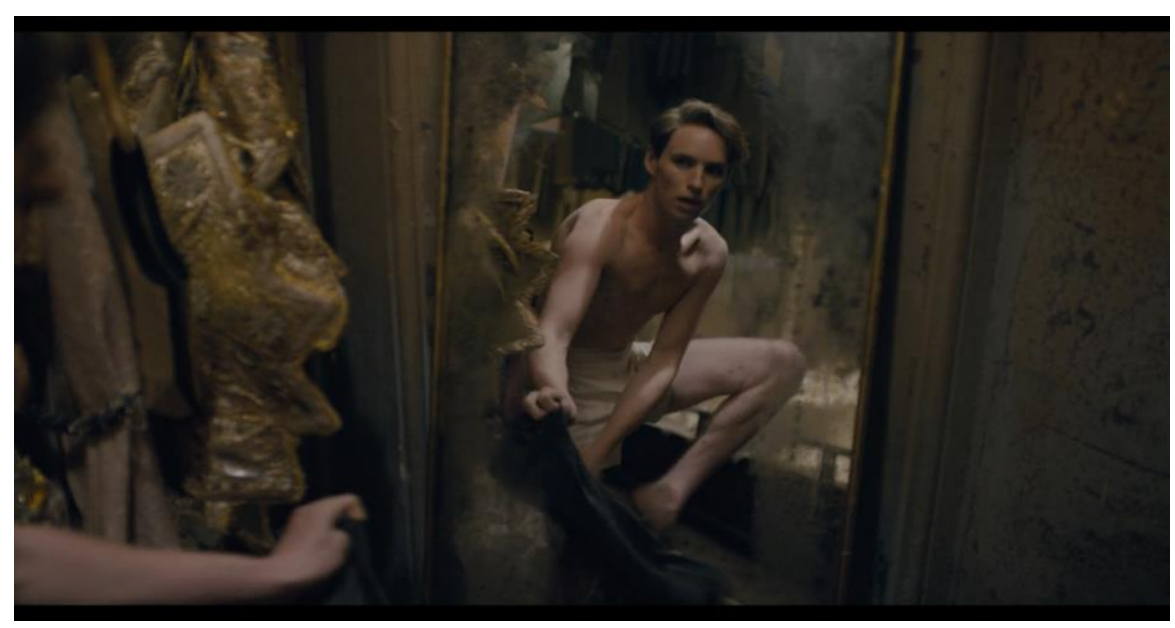

Fonte: A garota dinamarquesa (2015).

Vê-se na alternância dos closes entre seu corpo e rosto, a passagem de sentimento entre descontentamento e compreensão, quase alívio, pois começa a entender o que se passa com ele; o/a espectador/a convidado/a passar pelo mesmo, numa variação entre imagens-afecção e imagenspercepção, permeadas por imagens-ação que dão força ao sentimento vivenciado.

Figura 5 - No processo de experimentação

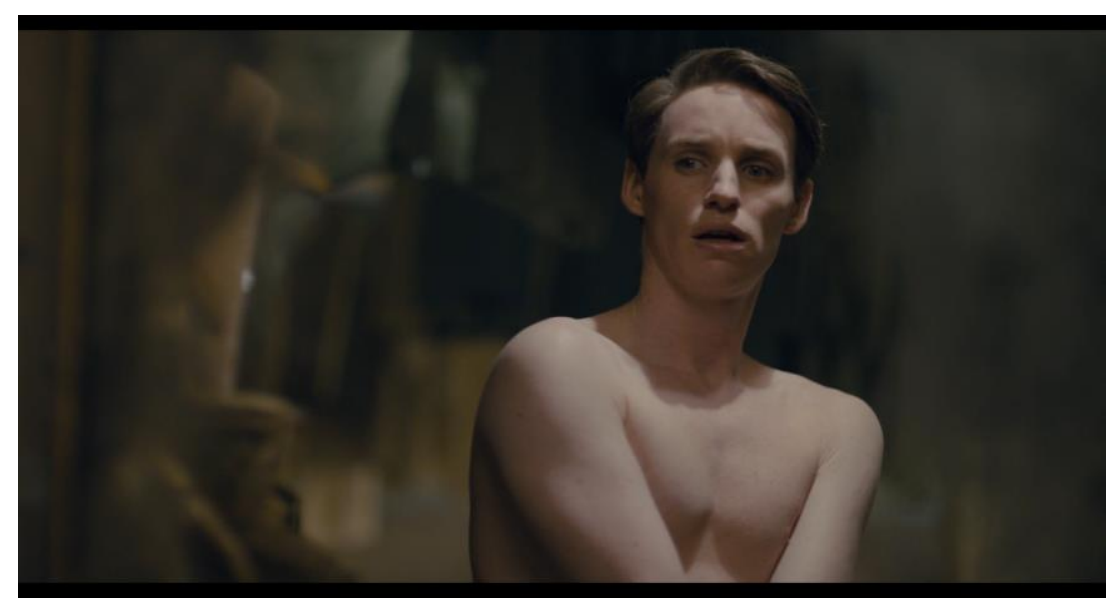

Fonte: A Garota Dinamarquesa (2015). 
A cena culmina com Einar escondendo seu pênis por entre as pernas (Fig. 6), simulando uma vagina. Isso novamente é tratado pelo diretor como primeiro plano, no processo de rostificação de reconhecimento do que está ali. Há uma percepção embutida num processo de sentir, com uma passagem que leva ao seu rosto novamente, agora sorrindo. Ao passar a mão pelo corpo, Einar se compreende dessa forma, sente-se dessa forma. Entende sua identidade assim e se sente bem assim (Fig. 7).

Figura 6 - O desaparecimento do órgão genital masculino

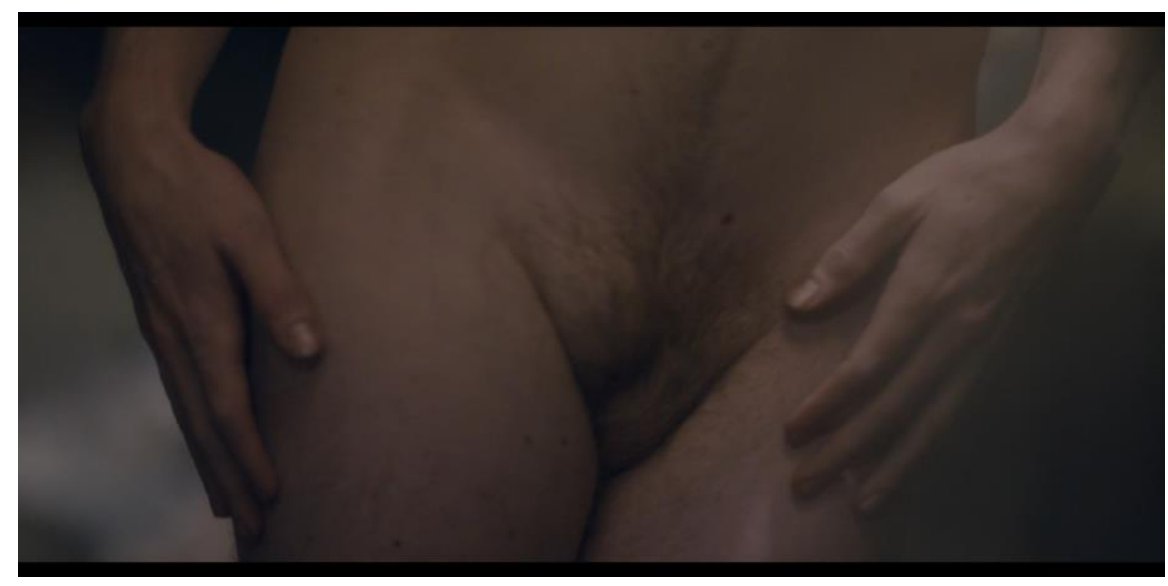

Fonte: A garota dinamarquesa (2015).

Figura 7 - O sorriso no processo de identificação

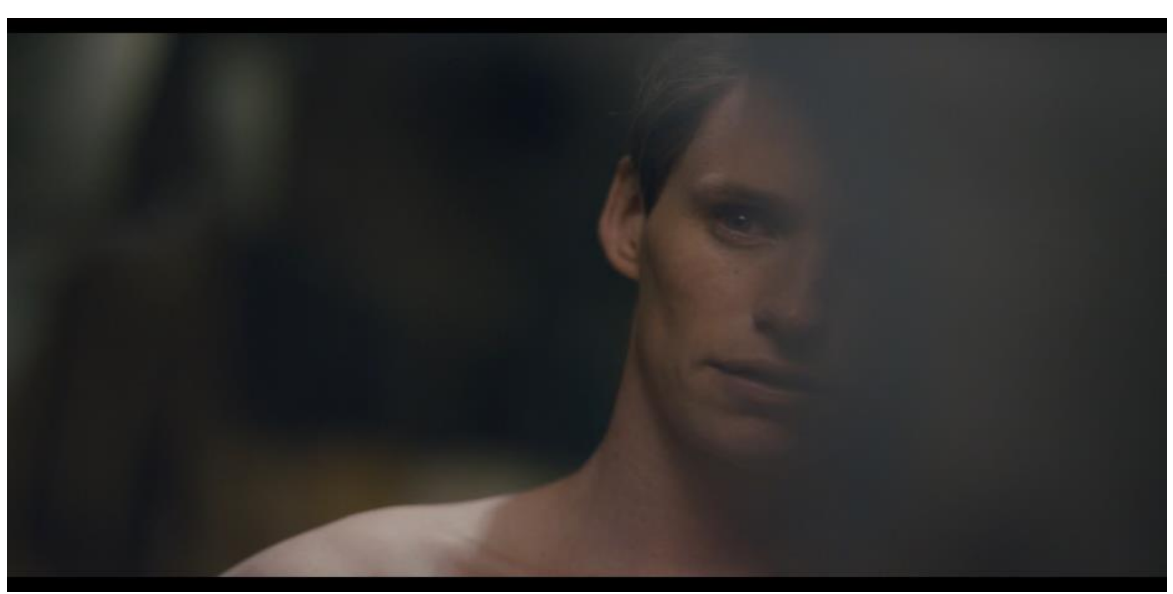

Fonte: A Garota Dinamarquesa (2015). 
O convite feito ao espectador/a durante a passagem de movimento culmina na percepção da identidade de gênero do personagem. Dependendo da vivência prévia do/a espectador/a, pode haver felicidade empática ao personagem ou não. Mas há uma questão de rosticidade forte nesse sentido, uma predominância da imagem-afecção na busca de um sentir empático com relação ao personagem. Einar se torna Lili, com um sorriso que demonstra sua felicidade ao perceber seu local identitário, num mundo que não necessariamente pode refletir o que se é. É neste momento de imagem-pulsão, em que se faz uso das transições de primeiro plano e plano médio, que se torna possível constatar o processo de percepção ao gênero feminino do/da personagem, por parte do/a espectador/a. Logo, há uma questão estética em transição para algo ético de conduta. $O$ sentimento se firma em realidade, algo que potencializava ser, torna-se.

Sobre as relações de gênero construídas pelo filme, a partir do aporte teórico dos Estudos Queer, observamos que o personagem Einar Wegener (Eddie Redmayne) desconhecia sua percepção enquanto mulher, que fora despertada somente quando sua esposa Gerda Wegener (Alicia Vikander), também pintora, pede para ele posar no lugar da modelo e amiga Ulla (Amber Heard). Seu contato com o tecido do vestido parece ter the revelado uma afeição à feminização, até então encoberta pela "incoerência" dessa possibilidade, ou melhor, impossibilidade.

O filme apresenta algumas cenas que demonstram Einar como um homem mais sensível, atento aos detalhes - características mais próximas ao padrão estabelecido para as mulheres -, por exemplo, quando Gerda diz que foi estranho ao beijá-lo pela primeira vez, pois "parecia que estava beijando a mim mesma"; a transexualidade do personagem é caracterizada como uma descoberta depois de uma vida vivendo de acordo com o comportamento masculino, exercendo seu papel de marido, protetor e provedor da casa. Embora ele reconheça, ainda que não tão claramente, seu desprendimento com o gênero masculino. Ao conversarem sobre o Baile 
dos Artistas, esse sentimento se torna um pouco mais evidente, quando ele declara que esses eventos "é bom para ser visto", por isso, não deseja ir, "é como se eu interpretasse a mim mesmo", o que indica sua inadequação ao gênero masculino, mas ao mesmo tempo, a necessidade de interpretar a "si mesmo", assumir uma postura masculinizada. Essa sujeição forçosa ao papel de homem que deve desempenhar, qual lhe foi atribuída ao nascer, expõe a matriz de normas de gênero que estamos todos/as submetidos/as, ao que Butler (2003) atribui de ordem compulsória da heterossexualidade, que estabelece padrões pré-determinados, sob uma ordem sempre binária e falsamente naturalizada.

Mas justamente por ser uma norma imposta, podemos nos ajustar ou não a esses padrões, e quando o sujeito se percebe inadequado ao gênero dado, torna-se muito penoso ter que cumprir com as funções e os papéis estabelecidos para este gênero (pré)determinado. Contudo, são nessas relações consideradas transgressoras que surgem as possibilidades de subversão, e estas sim, partem da intenção e desejo natural do sujeito. 0 filme retrata isso quando Einar observa a camisola nova de sua esposa, que comenta ser bonita; passados alguns dias, Gerda está nua no quarto e ao tirar a roupa de Einar, ele está vestido com a camisola, ela toca em seu peito, de modo como se ele fosse uma mulher, ele demonstra, assim, uma expressão de satisfação e realização ao se colocar numa posição feminilizada, passiva, como se ocupasse o lugar do feminino naquela relação sexual. Mesmo que sem a intenção deliberada de fazê-lo.

Outro ponto a destacar se refere ao momento em que Gerda lança a ideia de Einar ir ao baile de Lili, ambos levando na brincadeira. Para isso, porém, Einar precisa aprender a se comportar como uma mulher: maquiarse, vestir-se, sentar-se, gesticular-se, caminhar de salto alto, ou seja, passa pelo mesmo processo de aprendizado que qualquer menina (determinada como menina no nascimento) passa em nossa sociedade, que desde muito jovens, crescem ouvindo: "senta direito", "fale baixo", "não 
seja grosseira" e assim por diante. A delicadeza e submissão são ensinados e reforçados ao longo do tempo, não são características essenciais de uma mulher. Ao aprender a se comportar como uma dama, Lili, assim como as experiências transexuais, revela que todos/as aprendemos a ser homens e mulheres, isso denuncia o caráter performativo de nosso comportamento, ensinados e repetidos de geração a geração. A princípio, parece que Lili está atuando - ou parodiando o gênero feminino, como diria Butler, mas todos/as nós atuamos em nossas identidades generificadas, executamos as performances de gênero que nos foram estipuladas.

Por isso mesmo, é Gerda, sua esposa, quem o ajuda a se desempenhar como mulher. Lili tem em Gerda um modelo da feminilidade, pois ao nascer num corpo determinado como mulher e, ao mesmo tempo, identificar-se com os parâmetros do feminino, Gerda tem sua feminilidade legitimada, sua "performance" no gênero feminino é incontestável, pois se deu ao longo de toda sua vida, desde o nascimento. Assim, comporta-se como uma mulher de acordo com os padrões estabelecidos para o gênero feminino, atuando numa espécie de tutora para Lili. Isso a faz se sentir culpada quando Einar declara que não pode mais deixar de ser Lili, sentindo-se responsável pela condição dele, o que revela seu desconhecimento sobre a transexualidade, que apenas fora despertada num determinado momento, mas sempre existira.

Lili, por sua vez, também passa a lidar com as implicações que envolvem o gênero feminino, antes desconhecido enquanto homem. No baile, sente-se constrangida com os olhares que são depositados nela. Gerda declara que ela é bonita, então, "deve se acostumar", porque os papéis heteronormativos foram assim produzidos e pré-determinados; as mulheres devem se acostumar com os olhares masculinos, como numa espécie de exposição, que se arrumam para que sejam escolhidas por um desses olhares. Em nossa sociedade, aprendemos que a validação de uma mulher se dá, entre outras coisas, por meio de seu parceiro. Isso é encarado 
de forma natural para alguém que desde o nascimento aprendeu a ser uma menina, mas para Lili, tudo ainda é muito estranho, novo, nessa experiência de inversão de papéis.

Apesar de se sentir bem no gênero feminino e querer se comportar como tal, sente-se incomodada com a situação de estar submetida aos olhares masculinos. Gerda, que sabe como é estar deste lado, afirma que está tudo bem, que Lili só não está à vontade ainda. Esta cena remete a uma frase importante que Gerda afirma para um homem no começo do filme, ao pintar seu retrato: "É difícil para um homem ser observado por uma mulher; as mulheres estão acostumadas, é claro, mas para um homem, submeter-se ao olhar feminino é constrangedor. Embora, eu creio que seja possível ter algum prazer depois que você cede". Mais uma vez, podemos perceber como estes papéis, que são rigidamente estabelecidos, podem ser rompidos, ao subvertermos essa ordem, ainda que dentro do que já se conhece culturalmente, desestabilizando-a e enxergando, dessa maneira, as muitas possibilidades de construir nossas identidades generificadas e sexuadas.

O filme mostra a questão da transexualidade sob um viés sutil, através de uma representação construída mais por imagens e expressões do que diálogo. Há indicações dos sentimentos e sensações da personagem, mas não explicação, propriamente, sobre sua experiência transexual. Ainda assim, através dessa construção fílmica, é possível perceber as nuances que cada gênero tem de encarar e cumprir na sociedade. Fica claro no filme, ainda que de forma subjetiva, o quanto internalizamos os atos repetitivos de gênero - suas performatividades. Lili demonstra isso a caminho do baile, quando pergunta para Gerda se está "bonita o bastante", essa preocupação - antes inexistente - assume a obrigatoriedade que é imposta às mulheres em como "se deve" estar bonita. São termos de uma ordem compulsória heterossexista e, por isso mesmo, a importância de refletirmos sobre esses papéis que nos são impostos, para que tenhamos possibilidades outras 
construídas por/entre as fronteiras transgressoras, portanto, subversivas, que permitem maior autonomia do sujeito.

\section{Considerações finais}

Dadas as análises feitas anteriormente, a taxonomia apresentada por Deleuze se faz pertinente na compreensão da forma fílmica de A Garota Dinamarquesa, identificando pontos de imagem-movimento em afecção e pulsão para a percepção das questões de gênero observadas nas teorias butlerianas. Nesse sentido, o diretor Tom Hooper buscou retratar o modo como a identificação de gênero se dá num processo de autopercepção, utilizando da vivência prévia do espectador, levando-o/a a um estado de catarse estética através das imagens-afecção e imagem-pulsão quando da observação do personagem Einar na frente do espelho. A análise taxonômica deleuziana, de fato, responde ao entendimento do processo de montagem fílmico, onde se percebe, de forma detalhada, a movimentação de câmera e de corte na importância da composição da forma emocional da cena.

Já as relações de gênero abordadas no filme, foram retratadas de modo hiper-realista, dentro de uma perspectiva deleuziana, em que a experiência transexual da personagem Lili se deu através da demonstração de suas emoções e não, necessariamente, por meio de explicitação. Nisto, uma subjetividade pode ser notada no contexto da apreciação dos conceitos de gênero imbuídos na montagem e no movimento do filme, em que as atuações e falas sobre a transexualidade, eventualmente, estão implícitas. Ainda assim, identificamos uma proximidade com os conceitos de Butler, no que diz respeito à performatividade de gênero, ao mostrar como a personagem precisou aprender a se comportar no gênero feminino, assumindo seu papel enquanto mulher na sociedade. 


\section{Referências}

A GAROTA DINAMARQUESA. Direção de Tom Hooper. Produção de Tom Hooper, Eric Fellner, Gail Mutrux, Tine Bevan e Anne Harrison. Estados Unidos/Inglaterra. 2015. Distribuidora Universal. 1DVD.

BUTLER, Judith. Problemas de gênero: feminismo e subversão da identidade. Rio de Janeiro: Civilização Brasileira, 2003.

DELEUZE, Gilles. Cinema 1: a imagem-movimento. São Paulo: Brasiliense, 1983.

DELEUZE, Gilles; GUATTARI, Félix. Mil platôs: capitalismo e esquizofrenia. São Paulo: Editora 34, 1999.

DRIGO, Maria Ogécia; SOUZA, Luciana Coutinho Pagliarini. Aulas de semiótica peirceana. São Paulo: Annablume, 2013. 